total US defence spending. Flat too has been support for the International Atomic Energy Agency - the watchdog responsible for ensuring that national civil nuclear efforts remain civil - which remains hamstrung by the lack of any official remit to tackle the newer threat of nuclear terrorism (see Nature 451, 745; 2008).

The know-how to make a rudimentary nuclear weapon is already out there in the wild and cannot be recalled. But non-state players lack the means to produce the base fissile material needed: either highly enriched uranium (HEU) or plutonium. Blocking the theft or diversion of the vast stockpiles of these materials worldwide is therefore the most urgent issue for the international community.

$\mathrm{HEU}$ is the biggest worry. A plutonium device involves compressing a sphere of the metal with high explosives and would be a stretch for terrorists. An HEU device, by comparison, is child's play, demanding little more than a few dozen kilograms of the material and a simple mechanism to achieve a high-speed collision. Even a fizzle of an HEU device would take out most of Manhattan.

Incomprehensibly, there is no complete inventory of HEU stocks. But some 50 or so tonnes of it is thought to be stored in poorly secured civilian facilities worldwide, according to estimates by the Nuclear Threat Initiative in Washington DC. Most of that is used for research and medicine, for example in neutron sources and the production of medical isotopes. Low-enriched uranium (LEU) alternatives are available in almost all cases, but the extra costs involved, and the reactor redesign and extra research needed, have hampered efforts to switch over.

That some 272 HEU reactors in
"Incomprehensibly, there is no complete inventory of stocks of highly enriched uranium."
56 countries remain largely unsecured is simply unacceptable. All civilian HEU facilities must either promptly switch to LEU or be given military-level security.

Securing HEU is just one of many non-proliferation issues - from Iran and North Korea to reductions in arsenals and missile defence that will be on Obama's plate. But the time is ripe for a renewed global non-proliferation effort to avoid the world having to ask the day after a nuclear terrorist attack: "How did we fail to see this coming; why didn't we do something about it before?"

\section{A lifesaving arrangement}

\section{George Bush's AIDS programme needs leadership and support from the Obama administration.}

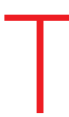

he focus of president-elect Barack Obama's incoming administration is understandably green jobs and a stimulus package to revive the flagging economy. But officials should not neglect one of George W. Bush's few well-received initiatives: the President's Emergency Plan For AIDS Relief (PEPFAR).

Unveiled in 2003, PEPFAR is a massive international programme to help those infected with HIV. More than 2 million people have been treated under its auspices, and it is widely hailed for proving that lifesaving AIDS treatments can be administered anywhere in the world - even in very poor countries where health systems were thought to be inadequate for the task (see page 254). But the programme now faces a long list of challenges. The first is to rid itself of scientifically unsound restrictions that prevent it from meeting its full potential. Examples include rules, imposed to satisfy the US religious right, that committed part of its funds to education on sexual abstinence and that made it difficult for organizations receiving PEPFAR funds to work with people at high risk of contracting HIV, such as prostitutes. The abstinence provisions have now been softened, but many restrictions remain, such as ill-advised policies preventing PEPFAR funding recipients from integrating with family-planning groups.

Another challenge is to convince Congress to spend the $\$ 48$ billion it authorized for the programme's continuation last summer - before the domestic and world economies imploded. Yet another is to expand PEPFAR to reach AIDS sufferers who still desperately need care.

Then there is the challenge of prevention, an area in which health officials acknowledge they have not made much headway, even as consensus grows that this is the key to stopping the epidemic. And perhaps most difficult of all is the challenge of sustaining PEPFAR in the future. AIDS cannot yet be cured, only held at bay. So PEPFAR must make a lifetime commitment to monitor the patients it is now serving, enrol them on antiretroviral treatment once they need it, and help them switch to new therapies as they develop drug resistance. This means that the programme will become much more expensive if it is to maintain its beneficial momentum.

For PEPFAR to navigate these challenges successfully, Obama will need to appoint a programme leader with scientific integrity and global stature. Meanwhile, PEPFAR's success abroad has led some to ask whether it is time for an equivalent programme within the United States, where public-health officials have stumbled badly in their efforts to fight the disease. Last year, the US Centers for Disease Control and Prevention in Atlanta, Georgia, revealed it had underestimated the number of new HIV infections by $40 \%$. There are serious
"The same stigma and denial driving the AIDS epidemic around the world can also be found in the United States."

barriers to HIV testing, such as inadequate policies to ensure people get tested and pay for the tests, and hundreds of thousands of those infected with the virus don't know they have it. The death in December of Christine Maggiore, an HIV-positive Los Angeles woman who argued that HIV does not cause AIDS, highlighted the fact that the same stigma and denial driving the epidemic around the world can also be found in the United States.

Doctors, activists and scientists have urged the United States to fill the vacant post of AIDS adviser at the White House to revitalize domestic efforts against the disease. They are also calling for a national AIDS policy to govern funding akin to PEPFAR's rules, under which aid recipients must explain how the funding fits their national goals to fight the epidemic. Obama should heed these calls, which would represent a significant step towards restoring the country's status as a leader in global health - both abroad and at home. 